\title{
玉軸受の䚓拌抵抗解析のための動解析*
}

\author{
西山 浩司 ${ }^{* 1}$, 井上 亜友子 ${ }^{* 1}$, 今田 大介 ${ }^{* 2}$, 長谷 陽夫 ${ }^{* 3}$, 戸倉 直 $^{* 4}$ \\ 篠田 淳一 ${ }^{* 5}$, 趙 希禄 ${ }^{* 6}$, 大島 修造 ${ }^{* 7}$, 萩原 一郎 ${ }^{* 8}$
}

\section{Dynamic Analysis for Investigation of Fluid Resistance for Ball Bearings}

\author{
Koji NISHIYAMA*1, Ayuko INOUE, Daisuke IMADA, Haruo NAGATANI, Sunao TOKURA \\ Junichi SHINODA, Zhao XILU, Syuzo OSHIMA and Ichiro HAGIWARA \\ ${ }^{* 1}$ Tokyo Institute of Technology. Dept. of Mechanical Science and Engineering \\ 2-12-1 Ookayama, Meguro-ku, Tokyo, 152-8550, Japan
}

Though the rolling ball bearing greatly contributes to decrease the friction energy of the machine movement, we require the development of lower friction torque technology of ball bearing to achieve more efficient machine. Especially, the fluid resistance makes an important role when the ball bearing is soaked in lubricant. Estimation of the loss of torque by the fluid resistance brings the reduction in the design cost. Therefore, in our research, it aims to develop the simulation technology of the fluid resistance by the ALE (Arbitrary Lagrangian and Eulerian) Finite Element Method. As the first step, we have established the simulation technology of movement analysis for the only ball bearing. In this report, we did the movement analysis numerical simulation of the ball bearing that considered the contact ellipse and EHL (Elastohydrodynamic Lubrication) Theory. As the result, we improved validity of the analysis from the perspective of the contact reaction force.

Key Words : Ball Bearing, Arbitrary Lagrangian and Eulerian, Contact Ellipse, Elastohydrodynamic Lubrication Theory

\section{1. 緒言}

転がり玉軸受は転走面と転動体が点接触であるため，線接触であるころ軸受と比べ低トルクであることから， 様々な産業機械の回転部支持に用いられており，機械運動の摩擦エネルギー低減に大きく貢献している．近年で は, 地球環境問題への対応として CO2 排出量削減へ向けた取組が加速されて, さらなる省エネルギー化や摩擦エ ネルギー低減が必要となり、転がり玉軸受にもより一層の低トルク化が求められている.

玉軸受のトルク損失の発生要因は主に次の 5 つである.

（1）軌道と転動体の間の転がり粘性抵抗

(2) 軌道と転動体間のすべり抵抗

（3）保持器と転動体間のすべり抵抗

(4) 潤滑剂と軸受の攪拌抵抗

（5）弾性ヒステリシス

従来の低トルク化手法は転がり粘性抵抗に着目しているものがほとんどであるが，軸受が多量の潤滑油で潤滑 される環境下において，攪拌抵抗を無視する事は出来ない(1). 攪拌抵抗とは，流体中を構造体が移動するとき受 ける抵抗であり, 流体の粘性や構造体の形状によって抵抗の大きさは変わってくる.このため, 転がり軸受内部

\footnotetext{
* 原稿受付 2011 年 10 月 25 日

*1 東京工業大学 理工学研究科（广152-8550 東京都目黒区大岡山 2-12-1）

*2 NTN (株) 自動車事業本部 CAE 技術部（厂438-8510 静岡県磐田市東貝塚 1578）

*3 正員, NTN (株) 自動車事業本部 CAE 技術部（广438-8510 静岡県磐田市東貝塚 1578）

*4 正員, (株) JSOL エンジニアリング本部 構造開発部（テ104-0053 東京都中央区晴海 2-5-24 晴海センタービル)

*5 インターローカス（厂152-8550 東京都目黒区大岡山 2-12-1）

*6 埼玉工業大学（干369-0293 埼玉県深谷市普済寺 1690)

*7 正員, 東京工業大学

*8 正員, フェロー, 東京工業大学

E-mail: nishiyama.k.aa@m.titech.ac.jp
} 
における潤滑油の流れ方や粘性によって，攪拌抵抗の大きさは影響され，軸受構造や潤滑油の物性值ならびに油 面高さなどの選択が非常に重要な課題となってくるが, その過程には回転速度や流入角度, 環境温度など運転条 件が異なる複数のパターンでの試行を要する．故に，数值シミュレーションにより攪䢁抵抗を事前に検討する事 ができれば，設計コストの大幅な削減が可能になると考えられる.

そこで，本研究では ALE（Arbitrary Lagrangian and Eulerian Method）有限要素連成解析法を用い，潤滑油と転が り玉軸受との間に生じる攪拌抵抗の影響を事前に検討できるシミュレーション技術を開発する事を目的とする.

その為には軸受構造解析シミュレーション技術の確立が前提条件であるため, 本稿では転がり玉軸受の構造解 析数值シミュレーションを行い，その妥当性を以下の $2 つ の$ 視点から検証を行った.

・転動体と外輪の間にはたらく接触反力

・内輪自転周期に対寸る転動体公転周期

計算手法として，接触楕円を考慮した接触反力と EHL（Elastohydrodynamic lubrication）理論による摩擦力を考 慮した計算式を導入する. 以下，解析の概要について述べる.

\section{2. 解析概要}

\section{$2 \cdot 1$ 解析条件}

本解析で用いた解析モデルを図 1 に示寸. 解析モデルは内輪, 外輪, 保持器, 底板が各 1 つずつと, 9 個 の転動体で構成されており，それぞれの要素数と要素種別を表 1 に示寸.また本解析では，モデルはすべ て剛体とし, 次頁以降に示寸接触剛性と摩擦力を考慮した。拘束条件を表 2 に示寸. 解析モデルは計算時 間短縮のため， z軸方向の対称性を考慮し $1 / 2$ 断面モデルを用いた.

Table 1 Number of elements

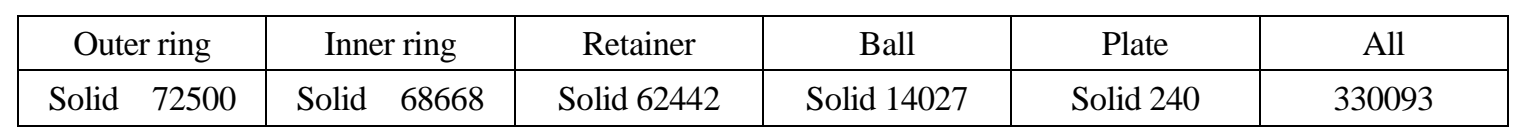

Table 2 Constraint condition

\begin{tabular}{|c|c|c|}
\hline Parts & Displacement & Rotation \\
\hline Inner & $x, y, z$ & $x, y$ \\
\hline Outer & $x, z$ & $x, y$ \\
\hline Ball & $z$ & $x, y$ \\
\hline Retainer & $z$ & $x, y$ \\
\hline Plate & $x, z$ & $x, y, z$ \\
\hline
\end{tabular}

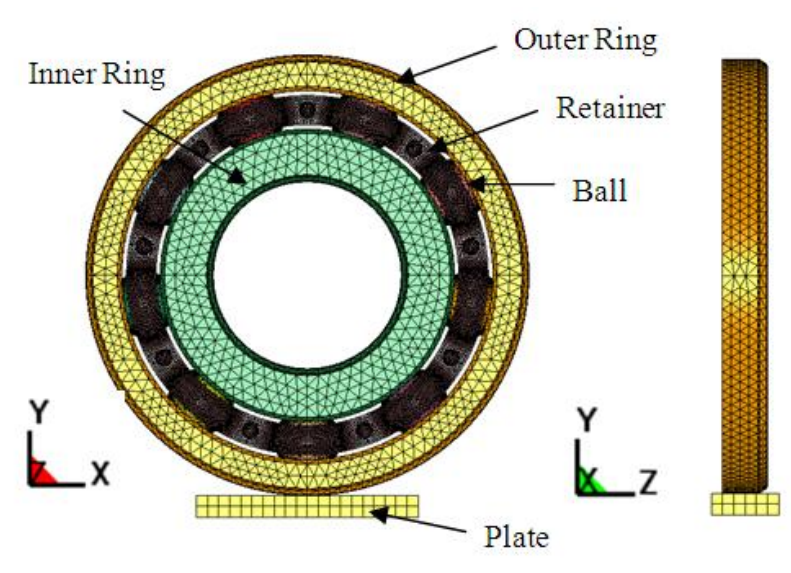

Fig.1 Ball bearing

底板 $y$ 軸正方向に 500[N]のラジアル荷重, 内輪 $z$ 軸周りに強制回転 1000[rpm] 加えた時の軸受の挙動を解析す る. 有限要素法のソルバーには非線形有限要素法の汎用プログラムである LS-DYNAver971R5.1 を使用した。転 動体と転走面や保持器の相対位置から, 幾何学的干渉が生じるとき, 接触反力, EHL 油膜による接線力が 2 物体 間に生じるものとする，以下，それぞれの計算方法について述べる. 


\section{$2 \cdot 2$ 接触棈円を考慮した接触反力}

剛体同士の点接触を考える際，その反力 $Q$ は干渉量 $\delta$ を表 3 に示寸接触剛性 $k$ の值を用いて式 (1) で表わすこと ができる.

$$
Q=k \delta^{m}
$$

Table 3 Contact stiffness

\begin{tabular}{|c|c|c|}
\hline Coefficient & Part & Contact stiffness \\
\hline$k$ & Ball-Outer & 910704 \\
\hline$k$ & Ball-Inner & 1279121 \\
\hline$k$ & Ball-Retainer & 275832 \\
\hline$k$ & Plate-Outer & 10000 \\
\hline$m$ & Common & 1.5 \\
\hline
\end{tabular}

しかしこれは 2 物体間が 1 点のみで接触している場合の接触反力の理論式であり，転動体被最大荷重時等，物 体同士が大きく干渉する際には複数点において接触する可能性があり，その場合誤差を生じてしまう．従来，線 接触に関しては接触領域をスライス寸る手法が提案されているが(2)，点接触ではその手法が見当たらない，そこ で本解析では接触楕円をスライスした場合の接触剛性式の導入を提案する. 以下，その理論について述べる.

理論を適用するため，図 2 に示すような転動体，内輪，外輪それぞれのモデルの接触領域を回転軸方向に 6 分 割したモデルを作成した.

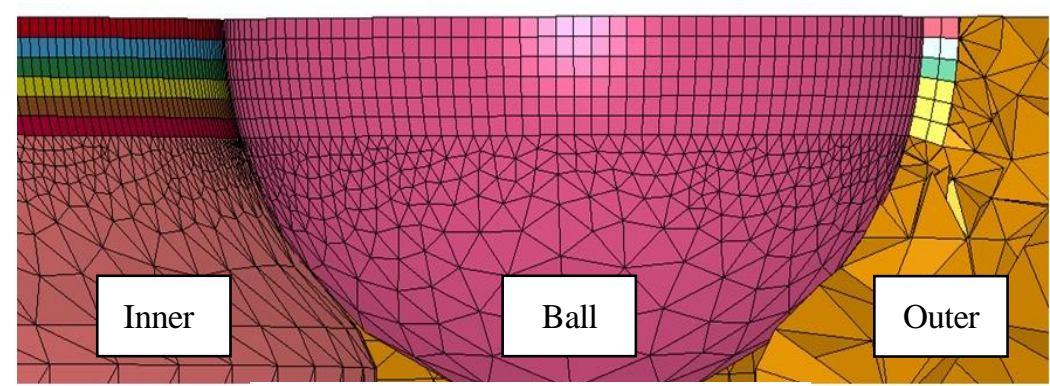

Fig. 2 Slice of contact area

転動体と軌道の接触において，面圧分布は図 3 のように楕円体状となり，(3)式で表わされる.

$$
p(x, y)=\frac{3 Q}{2 \pi a b} \sqrt{1-\left(\frac{x}{a}\right)^{2}-\left(\frac{y}{b}\right)^{2}}
$$

転走面を回転軸方向にスライスした場合, 各スライス片が支持する荷重はこの接触面圧を積分したものである. スライス片 $i か ゙ x$ 座標で $x_{a} \sim x_{b}$ の幅とすると, 支持する荷重 $q_{i}$ は図 3 でハッチングした領域を積分して求めること になる。

これを数式で表現すると次式のように表わされる.

$$
q_{i}=\frac{3 Q}{4 a}\left[\left(x_{b}-x_{a}\right)-\frac{1}{3} \frac{x_{b}{ }^{3}-x_{a}^{3}}{a^{2}}\right]
$$



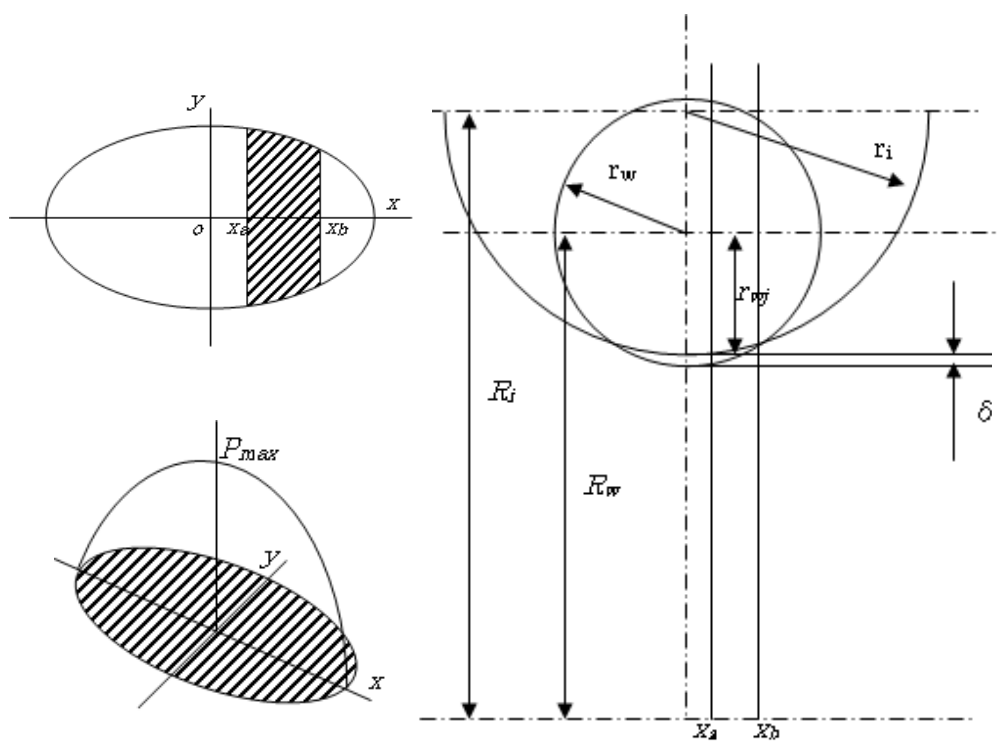

a radius of major axis

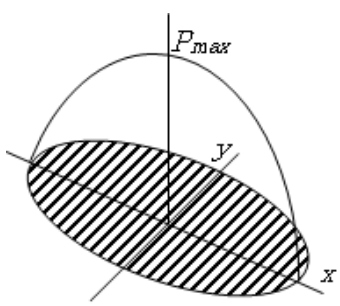

$b$ radius of minor axis $r_{w}$ radius of ball

$r_{i}$ radius of orbital path

$R_{w}$ distance of reference plane- ball

$R_{i} \quad$ distance of reference plane- orbital path

$x_{a}$ coordinate of each slice element (min)

$x_{b}$ coordinate of each slice element (max)

Fig. 3 Contact ellipse

接触楕円中央 $(x=0)$ における干渉量 $\delta$ と各スライス片中央における干渉量 $\delta_{j}$ の関係は式 (4) で表すことができ る。

$$
\delta=\delta_{j}+\sqrt{r_{i}^{2}-x_{j}^{2}}-\sqrt{r_{w}^{2}-x_{j}^{2}}-r_{i}+r_{w}
$$

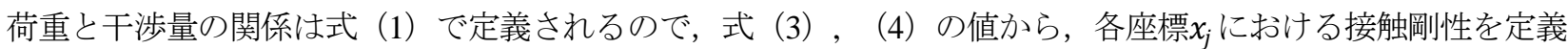
する事が可能となる.

$x_{j}=\left(x_{a}+x_{b}\right) / 2$ とすることで，各スライス列における干渉量 $\delta_{j}$ と荷重 $q_{i}$ の関係を導くことができる．導いた関 係式を式（5）に，各スライス列について計算した input1, input2 の值を表 4 に示す.

$$
q_{i}=\text { input } 1 \times\left(\delta_{j}+\text { input } 2\right)^{1.5}
$$

Table 4 Value of input1, input 2

\begin{tabular}{|c|r|r|r|r|}
\hline \multirow{2}{*}{$\begin{array}{c}\text { Slice } \\
\text { number }\end{array}$} & \multicolumn{2}{|c|}{ Ball-Outer } & \multicolumn{2}{c|}{ Ball-Inner } \\
\cline { 2 - 5 } input 1 & \multicolumn{1}{c|}{ input2 } & input1 & \multicolumn{1}{c|}{ input2 } \\
\hline 1 & 206044 & 0.00011 & 187755 & 0.00004 \\
\hline 2 & 141100 & 0.00097 & 165076 & 0.00033 \\
\hline 3 & 11212 & 0.00270 & 119717 & 0.00094 \\
\hline 4 & 0 & 0 & 51679 & 0.00186 \\
\hline 5 & 0 & 0 & 0 & 0 \\
\hline 6 & 0 & 0 & 0 & 0 \\
\hline
\end{tabular}

外輪の 4 6 列，内輪の 5 6 列目に関しては，幾何学的に接触は生じないため, input1, input2の值をそれぞれ 0 としている．表 5 の式を各スライス列と転動体間の接触の関係式として定義し，解析を行う.

\section{$2 \cdot 3$ EHL 油膜による接線力}

2 物体が接触している場合，その摩擦係数 $\mu_{r}$ は膜圧比（合成粗さに対する油膜厚さの比） $\Lambda$ 用いて式（6）の ように表せる(3). 


$$
\mu_{r}=\left\{\begin{array}{l}
\mu_{b d} \\
\frac{\mu_{b d}-\mu_{h d}}{(0.01-1.5)}(\Lambda-1.5)^{6}+\mu_{h d} \\
\mu_{h d}
\end{array}\right.
$$

境界潤滑下 $\left(\Lambda<\Lambda_{b d}\right)$ の摩擦係数 $\mu_{b d}$ は, Kragelskii の固体接触摩擦係数の関数 ${ }^{(4)}$ 式 (7)のように修正して用いた. 修正点は，変数をすべり速度からすべり率へ，またすべりが 0 の場合に摩擦係数も 0 となるようにした.

$$
\mu_{b d}=(-0.1+22.28 s) \exp (-181.46 s)+0.1
$$

流体潤滑下 $\left(\Lambda>\Lambda_{h d}\right)$ 摩擦係数 $\mu_{h d}$ は，式（8）に示す村木らの簡易理論式(5)を用いた.

$$
\mu_{h d}=\tau_{0} \bar{S} / \bar{P}
$$

\section{2・4 EHL 転がり粘性抵抗}

EHL 転がり粘性抵抗は，式（9）に示すZhou らの回帰式(6)を用いて求める事が出来る。しかし，EHL油膜に よる接線力に対して非常に小さいため今回は無視する事とする.

なお，Zhou らの回帰式は線接触を前提としたものであるが，点接触をスライスした場合にも適用できると考え る.

$$
F_{E H L}=\emptyset_{T} \frac{29.2 R_{e} l(G U)^{0.648} W^{0.246}}{\alpha_{0}}
$$

なお，今後流体要素の導入を行うにあたり，EHL 理論を考慮した解析システムを構築したが，本論文の解析に おいては構造のみの解析となるため，EHL 油膜による影響はない.

\section{3. 解析結果}

初めに内輪の自転周期と転動体の公転周期を比較する為に，内輪の 1 点及び転動体中心の $x$ 座標の変位の履歴

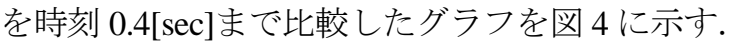

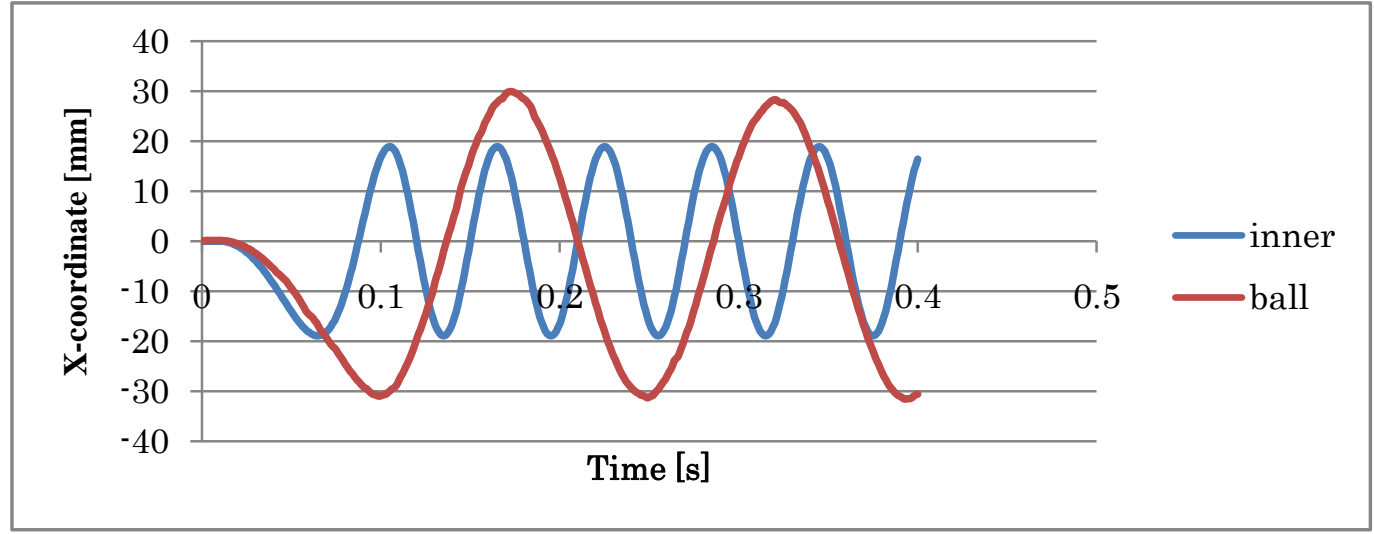

Fig.4 Time - X-coodinate 
この結果から内輪自転周期，転動体公転周期を求めると表 5 に示寸結果が得られた.

Table 5 Cycle of ball and inner ring

\begin{tabular}{|c|c|c|}
\hline Inner ring $[\mathrm{s}]$ & Ball[s] & Inner ring /Ball \\
\hline 0.06 & 0.149 & 0.403 \\
\hline
\end{tabular}

（内輪自転周期）/（転動体公転周期）の值は理論式から 0.401 と求められる(7). 解析值は 0.401 に程近い值を示 していることから，周期の観点において，解析は妥当であるといえる.

次に，転動体と外輪との間に生じる接触反力について検討する．転動体が最高点に位置している時を 0[degree] とし，時計回りに 1 周分，転動体が外輪から受ける反力を出力した。. また，静解析により得られた解析值を比 較対象とした ${ }^{(8)}$. その結果を図 5 に示す.

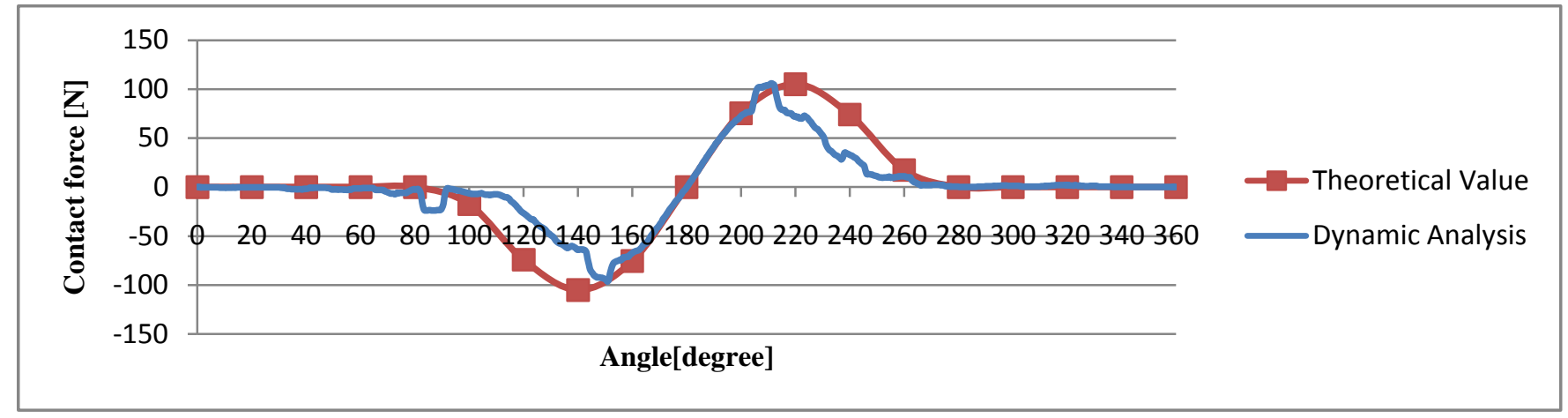

(a) $\mathrm{X}$-axis

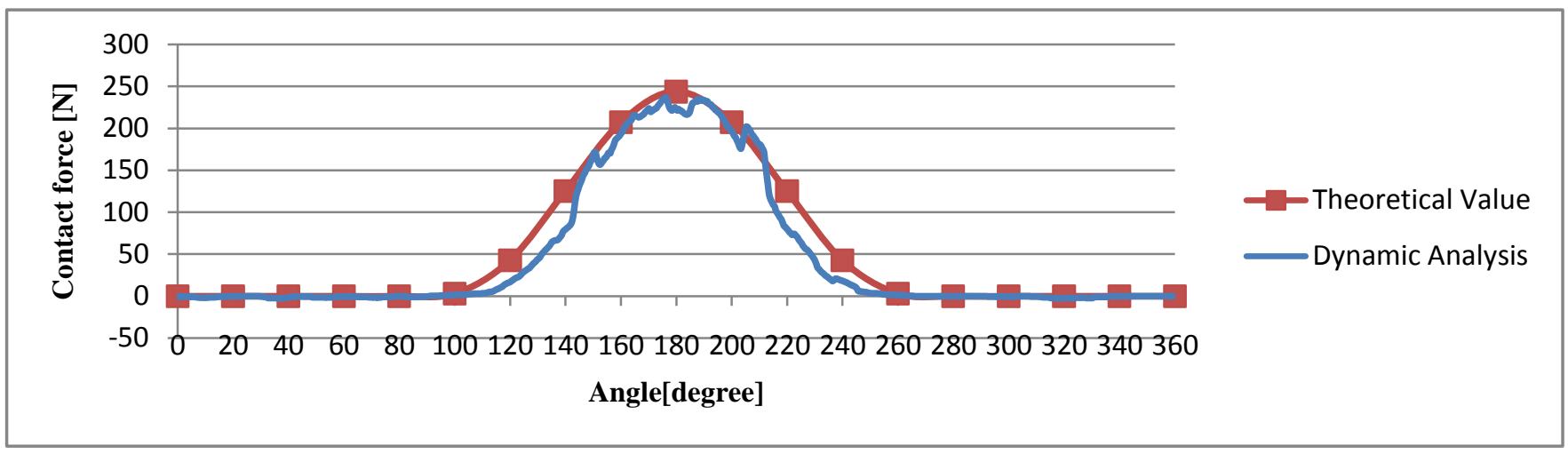

(b) Y-axis

Fig.5 Angle - Contact force

$y$ 軸方向の接触反力は静解析の結果とよく似た履歴を示している. $x$ 軸方向の接触反力は, 負荷領域が狭くなっ ているが，転動体最下点付近においては一致が見られる．玉軸受のトルク損失への影響が支配的である $y$ 軸方向 の接触反力と, 転動体最下点付近の $x$ 軸方向の接触反力が確認できたことから, 本解析はトルク損失を検討する 上で妥当性を有していることが評価できる. $x$ 軸方向の負荷領域が狭くなっているのは, 今回用いた各スライス 列における接触剛性の式が，転動体最下点時の理論式である為，誤差が生じたと考えられる．また，反力が振動 しているのは，接触部の回転軸方向のメッシュのつなぎ目が要因だと考えられる．より細かいメッシュを用いる 事で振動は抑制されると考えられる。 
以上の結果から，提案した手法による解析シミュレーションは，今回の解析条件下において妥当性を有してい る事が確認できた.

\section{4. 結語}

本稿では，接触楕円を考慮した接触反力と EHL 油膜による接線力を導入した動解析を行い，(内輪公転周期）/ （転動体自転公転周期）の值と転動体-外輪間にはたらく接触反力の值という 2 つ観点から解析の妥当性を検証 し，玉軸受の動解析シミュレーション技術を確立した。この手法を用いる事で，設計段階においてあらゆる玉軸 受構造に対し，生じ得るトルク損失の予測が可能となる．今後，この手法に ALE 有限要素法を導入し，玉軸受に おける攪拌抵抗の解明を行う。具体的には，今回用いた玉軸受メッシュを潤滑油メッシュ要素で浸し，構造部分 は本稿と同じく Lagrange 要素, 流体部分はALE 要素として連成解析を行い, 流体の挙動やトルク損失の值から 攪拌抵抗解明にアプローチしていく.

\section{文献}

(1) Gupta, P. K., Advanced Dynamics of Rolling Elements(1984), Springer-Verlag, Chap.5, pp.100.

(2) Harris, T. A., "The Effect of Misalignment on the Fatigue Life of Cylindrical Roller Bearings Having Crowned Rolling Members", Transaction of the American Society of Mechanical Engineers, Journal of Lubrication Technology, Vol.91, F, No2, (1969), pp.294-300.

(3) Sakaguchi, T., and Harada, K., "Dynamic Analysis of Cage Behavior in Tapered Roller Bearing", Transaction of the American Society of Mechanical Engineers, Journal of Tribology, Vol.128, No3 (2006), pp.604-611.

(4) Kragelskii, I. V., "Friction and Wear, Butterworths", London (1965) , pp.178-184.

(5) 村木 正芳，木村 好次，“潤滑油のトラクション特性に関する研究 (第 2 報)”, 非線形粘弾性モデルによるトラク ションの熱的解析潤滑，28, 10(1983), pp.753-760.

(6) Zhou, R. S., Hoeprich, M. R., "Torque of Tapered Roller Bearings", Transaction of the American Society of Mechanical Engineers, Journal of Tribology, Vol.113, No7 (1991) , pp.590-597.

(7) 曾田範宗, “軸受”, 岩波書店(1964), pp.92-94.

(8) Jones, A. B., “A General Theory for Elastically Constrained Ball and Radial Roller Bearings Under Arbitrary Load and Speed Conditions", Transaction of the American Society of Mechanical Engineers, Journal of the Basic Engineering, Vol.82, No.1, (1960), pp.309-320. 